\title{
ARTIFICIAL INTELLIGENCE AND PHILOSOPHICAL CREATIVITY: FROM ANALYTICS TO CREALECTICS ${ }^{1}$
}

\author{
LUIS DE MIRANDA
}

\begin{abstract}
The tendency to idealise artificial intelligence as independent from human manipulators, combined with the growing ontological entanglement of humans and digital machines, has created an "anthrobotic" horizon, in which data analytics, statistics and probabilities throw our agential power into question. How can we avoid the consequences of a reified definition of intelligence as universal operation becoming imposed upon our destinies? It is here argued that the fantasised autonomy of automated intelligence presents a contradistinctive opportunity for philosophical consciousness to understand itself anew as holistic and co-creative, beyond the recent "analytic" moment of the history of philosophy. Here we introduce the concept of "crealectic intelligence", a meta-analytic and meta-dialectic aspect of consciousness. Intelligent behaviour may consist in distinguishing discrete familiar parts or reproducible functions in the midst of noise via an analytic process of segmentation; intelligence may also manifest itself in the constitution of larger wholes and dynamic unities through a dialectic process of association or assemblage. But, by contrast, crealectic intelligence co-creates realities in the image of an ideal or truth, taking into account the desiring agent imbued with a sense of possibility, in a relationship not only with the Real but also with the creative sublime or "Creal".
\end{abstract}

Key words: artificial intelligence; technology; analytics; crealectics; metaphilosophy.

\section{Introduction: Making sense of the forest of the real}

The growing entanglement of humans, digital machines and artificial intelligence (AI) creates "anthrobotic" protocols that challenge our philosophical reflection (de Miranda, Ramamoorthy, \& Rovatsos, 2016). Whenever we overlook that AI operates under human interpretation and design, dramatic or anxiogenic narratives seem unavoidable in that $\mathrm{AI}$ may be expected to outsmart humanity in the capacity to think (Geraci, 2008). But despite the widespread use of the phrase "artificial intelligence", there is no universal agreement on what intelligence is. How can we then differentiate what, on the one hand, machines could

1 This work has been supported by the European Union's Horizon 2020 research and innovation program under grant agreement No. 825619 (AI4EU). 
make sense of and what, on the other hand, humans can think fruitfully about in a nonautomated fashion?

The very etymology of the word intelligence is ambivalent between the two Latin roots inter-legere and inter-legare. As explained by anthropologist Marcel Jousse (2016), intelligence can be about inter-legere, to discriminate: "the world is an immense chaos of interactions, but in this immense chaos of interactions comes a human being who will know how to choose from this multiplicity" (p. 29). But the root of intelligence could be interligare: "to link up in the form of interactions [...]. Remember the great Laplace: Discoveries consist of bringing together ideas - I would say facts - that are susceptible to join but that had not been hitherto been joined" (Jousse, 2016, p. 29). Whether intelligence consists in picking and distinguishing parts by a process of division and segmentation, in discovering wholes, syntheses and unities by a process of association, or in organising actualisations of possibilities - not to speak of the various historical, cultural and disciplinary variations in defining intelligence around the globe - this polysemy points to the necessity of not speaking of intelligence as if it were one universal form of manipulating symbols.

What should we mean, then, when we speak of AI? In what follows, I explain why $\mathrm{AI}$ as we know it is for the most part a display of analytic intelligence. It is dominantly implemented in the real world as a set of algorithms facilitating predictive analytics or data analytics, defined as forecasting the statistical likelihood of future actions, trends or patterns [...] on the basis of inferred relationships between variables in recorded data (Chandler \& Munday, 2016). In other words, AI is a human-designed digital technology that facilitates the identification of meaningful patterns within bodies of data through the use of computers, and the prediction of future patterns, in order to gain insights that facilitate an automated action or a human decision.

The specialisation of AI in analytic operations sheds a renewed light, by contradistinction, on the creative and cosmological aspect of philosophical intelligence, an aspect that was sometimes disparaged or forgotten in the recent "analytic moment" of the history of philosophy. This meta-analytic aspect of consciousness we call crealectic intelligence, because it is a form of hyper-dialectic (Merleau-Ponty, 1968) that relies on the axiom that the ultimate Real, the forest of all experiences, is also a "Creal", an infinite and continuous creation of multiplicity and possibility (de Miranda, 2017). In order to fully intuit what crealectic intelligence might be in the light of our anthrobotic horizon (part 3), we will contrast it with analytic intelligence (part 1) and dialectic intelligence (part 2).

\section{The pebbles in the forest: Analytic intelligence and AI}

What does the so-called automation of intelligence mean for philosophy? In order to understand the relevance of crealectics, or creative philosophy, we firstly contrast it with the logic of its dialectical counterpart, mechanised analytic intelligence. An enabling set of algorithms is primarily an analytic machine. Analytics is the dominant approach to intelligence in our engineer-driven societies because it is more easily decomposed and mathematised into sets of operations. Analytics needs decomposable material as the primary component for its manipulation of numerical symbols. This is compatible with automation and so-called evidence-based decision-making. 
Analytic forms of intelligence were certainly a major step in human evolution. Some eighteen centuries ago, in his account of Aristotle's Analytics, Alexander of Aphrodisias wrote that the one who "uses analysis [...] reduces composite bodies into simple bodies" (c.200 CE, 49, §2.4), thus separating an unknown into parts that are known (Arnauld \& Nicole, 1996, p. 200). The telos of current automated analytics was anticipated by Laplace (1814), who famously believed we ought

to regard the present state of the universe as the effect of its anterior state and as the cause of the one which is to follow. Given for one instant an intelligence which would comprehend all the forces by which nature is animated and the respective situation of the beings who compose it-intelligence sufficiently vast to submit these data to analysis-it would embrace in the same formula the movements of the greatest bodies of the universe and those of the lightest atom; for it, nothing would be uncertain and the future, as the past, would be present to its eyes (Laplace, 1814, p. 4).

This deterministic, quantitative and homogenizing telos is reactivated in the dominant discourse of AI.

But some inventors of computational thinking were already aware that an essential part of intelligence was left behind in their endeavours, namely a relationship to creation and truth. When Charles Babbage and Ada Lovelace designed the first "Analytical Engine" by associating analysis with a mechanical function of "operation" (Menabrea, 1961, p. 247), Lovelace was careful to add: "The Analytical Engine has no pretensions whatever to originate anything. It can do whatever we know how to order it to perform. It can follow analysis; but it has no power of anticipating [...] relations or truths." (p. 284).

Beyond this "Lovelace Objection" to AI (Turing, 1950), there is what we might call the Whitehead Objection to the belief that analysis and concreteness are sufficient to understand the Real: analytics, while useful for purposes of manipulation and operationality, often ends up mistaking the abstract object for the concrete in a "fallacy of misplaced concreteness" (Whitehead, 1926, p. 64). Out of habit or cognitive bias, we tend to believe that the parts, units or functions that we distinguish and name, are truly there in the real world, like cogs in a machine. By analogy, digital worlds and AI-based "virtual reality" seem to be for our minds more and more indistinguishable from IRL ("in real-life") experiences. But such a phenomenon happens precisely because our cognition is not only analytic but also creative, as confirmed by recent trends in neuroscience (Berthoz, 2012): our consciousness produces semblances of emergence and meaning that supersede the sum of the observed parts and cannot be explained by strict analysis (Murphy \& Stoeger, 2007). In the past, analytic philosophers, tempted by materialism and the ideology of concreteness, have ironically called this surplus of meaning the "ghost in the machine" (Ryle, 2009 [1949], p. 5). But to call what we experience, but cannot fully analyse, measure, demonstrate or show, a "ghost" or "superstition", partakes in a reductionism that can be "detrimental both to good science and good human living" (Thompson, 1997, p. 219).

Analysis is certainly indispensable as a step that considers reality as readable, a corpus or text. Abandoned in the forest, Hansel and Gretel find their way home with white pebbles, even if this does not get them out of trouble in the longer run. Analysis is a moment of distinctive literacy facilitating communication and the effectual manipulation of the Real. If 
an intentional consciousness is not able to distinguish discrete parts in the world by reading them as potential text or even operating programme, it might remain dreamy and confused (Craig, 1984, p. 41). Analytic elements manifest as what Noam Chomsky called a "surface structure" (1968, p. 30). At the level of a written language, the surface structure is represented by discrete symbols such as letters, code or forms. The analytic moment is the consideration of the world as possible syntax instead of chaos, or, in the language of AI, patterns versus noise. This is useful as an effectual reading of the surface structure; but analytic intelligence becomes a reductionist worldview when it claims to describe the depth of the Real.

In order to avoid the illusion that AI can be "intelligent" without human intervention, we need to remember that the possibility of an interpretation or semantic deciphering of an environment is a subjective component of intelligence, a perspective. Even prominent computer scientists like Stuart J. Russel now claim that in order to gain insights that improve meaningful decision-taking, AI needs the help of an interpreter, a subject who is part of a "web of belief" (Quine \& Ullian, 1978), deciding what is pertinent and what is neglectable depending on a given purpose (Russell, 2019). Making sense of the random noise of data is an interpretation modelled on an observer- or subject-dependent perspective (Kaan, 1999). For the psychologist Piaget, intelligent behaviour involves a process of centration, of mental focus on such or such an aspect of reality made concrete: one pays attention to this rather than that, in a movement of intentional discrimination (Piaget, 1952). Concreteness is a useful "ensemblance" (de Miranda, 2020), but pure analysis cannot in itself provide meaning, nor creative unification.

Searle's famous distinction between syntax and semantics (1980) aimed at explaining why computers do not have an understanding of what they do and therefore cannot be said to be intelligent: "Computation is defined purely formally or syntactically, whereas minds have actual mental or semantic contents, and we cannot get from the syntactical to the semantic just by having the syntactical operations and nothing else" (Searle, 2010, p. 17). Whether one agrees with the syntax/semantics division or not, one might concede that analytic intelligence as it is practiced in our anthrobotic culture implies four procedures (not always in the following order): a moment of selection or distinction between useful data and neglectable noise; a moment of decomposition or division of a whole into parts and operations; a moment of reification, the transformation of continuous processes into discrete articulated objects; a moment of digitization, the reduction of the parts into computable symbols. In fact, as will be argued below, all these moments imply a discursive negotiation and a creative focus that requires the concurrent display of dialectic and crealectic intelligences.

\section{Breadcrumbs in the forest: Dialectic intelligence}

Shared intelligence needs an analytic moment in order for agents to communicate their reading of a given situation. But once we start disagreeing with a given analysis or debating aspects of it, we are adding a dialectic dimension which functions as a bridge between analytics and crealectics.

Since Plato, dialectic intelligence designates an interpretative conversation in which there is a more or less rational tension between different or agonistic perspectives (from 
dialegesthai: to talk through). Dialectics is "the progression of thought through the appearance of oppositions within one and the same unity" (Bloch, 1983, p. 288). This form of thinking can be performed between different subjects or within the same personal mind, as in Socrates's inner dialogue with his guardian divinity, his daimonion (McMahon, 2013, p. 40), or as in Descartes' cogito, which can be defined as the human capacity for an internal individual dialectics, a form of consciousness that is capable of self-contradiction or selfexamination.

In Hegel's grandiose variant, dialectic intelligence described the ubiquitous and necessary unfolding of a time-dependent yet absolute process of negations and performative contradictions towards the realisation of Spirit. Hegelians believe that the Real is really dialectical, and therefore that dialectic intelligence is a privileged form of realism leading to objective knowledge: "the dialectical constitutes the moving soul of scientific progression" (Hegel, 1817, §81). In dialectic consciousness, a proposition and its opposite can be both true, thus apparently ignoring the law of non-contradiction common in analytic logic. To remember how such ambivalence is possible, we can invoke an example that is not the usual handbook illustration of Hegelian dialectics: consider human somatization, the idea that unhealthy mental or emotional states can remain unconscious and be manifested in bodily troubles. Manifesting a mental disorder or distress via physiological ways can be said to be a dialectic process: it is in some sense healthy to be able to ascribe psychological or existential conundrums to our bodies, because the physical symptoms make it possible to read that there is a problem before it is too late. A somatization is a relatively transparent way of manifesting existential problems that might otherwise remain unreadable; such manifestation may reveal, paradoxically, a relatively good communication between mind and body. A very simple example of somatization is crying; when Hansel and Gretel are crying in the forest, their exteriorised suffering makes them conscious that something is really wrong, and they can try to find a solution.

Individual, bilateral or collective forms of dialectic intelligence rely on polarities, tensions and potential contradictions in a process that is ideally moving towards a form of reconciliation, resolution or synthesis that should reflect the logic of the "World-Soul" (Hegel, 1806, p. 114). When fetishised as a one-fits-all tool, as in the Marxist variant, or the Sophists' version of the Ancient Greek variant, dialectics sometimes forces syntheses via deception or coercion. In Hansel and Gretel's tale, once the white pebbles cannot be accessed to mark the path, impermanent breadcrumbs are used, which may be dialectically perceived as symbols or as food. The birds win the competition for meaning by eating the crumbs. In the agonistic world of dialectics, the illusion might be that there is not enough bread for everyone and it becomes difficult to identify if a synthesis is logical and objective, or rather belongs to a subjective victory of one interest over another. Few can avoid being emotional in an antagonistic dialogue, and even Hegel admitted the importance of passion in dialectic unfolding. Hyper-communitarian times demonstrate the pitfalls of dialectics: any legitimate position can be considered a form of scandalous usurpation or vice versa, a phenomenon that is accelerated by AI chatbots and other digital echo chambers.

The dialectic stage of understanding is nevertheless necessary to transform a reading of signs into a deliberative interpretation that encompasses real or apparent contradictions. However, this moment of intelligence is not sufficient to act upon the world because the 
synthesis it proposes can be contested and, by definition, negated anew: if the world is only dialectically interpreted, it becomes an interminable process in which everything becomes negative and positive alternatively, any synthesis being an ephemerous plateau collapsing into a new thesis-antithesis dynamic. Moreover, dialectics tends to fall into binary dichotomies, which are themselves cognitive reductions, even if they seem to introduce more complexity than analytic intelligence (Elbow, 1993). For example, the two categories of disease and normal health are oblivious of possible alternative mental or physical states that are neither normal nor unhealthy (Canguilhem, 1991, p. 97). The human phenomenon of psychological resilience is neither pathological nor normal: it is a "novelty", a manifestation of crealectic intelligence (de Miranda, 2019).

\section{The cottage at the heart of the forest of the real: Crealectic intelligence}

Analytic and dialectic intelligences cannot exhaust our experience of intelligent agency. The analytic strategy of the white pebbles and the dialectic strategy of the breadcrumbs fail to solve the long-term problem of Hansel and Gretel, which is that their family is materially and spiritually poor. What saves them is the crealectic strategy of going deep into the forest and confronting the abyss of possibility and sublimity. They risk their lives by the gingerbread house of plenitude guarded by the primordial witch; and its oven of abundance which may dissolve or regenerate.

Social reality is polysemantic and implies a multiplicity of decisions and acts in which the very factualization of data, the attribution of a syntax to a given reality, is itself already filtered by creative and active imagination and an embodied perspective. We propose to call "crealectic" the existential form of consciousness that is aware of acting as an engaged person upon a world of multiplicity and possibility, with the ideal of co-creation in mind. Crealectic intelligence cannot be emulated by a non-biological AI because it is grounded in desire and felt sublimity.

Crealectics deals with processing realities and imaginaries of novelty, plurality and ambiguity, rather than mere contradiction of binary polarities or operation of known bits; its ontological core is the idea of creation understood ontologically as ubiquitous stream of infinite possibility (Bergson, 1922; Whitehead, 1929; Deleuze \& Guattari, 1994, de Miranda, 2017). The neologism crealectics comes from "Creal", a contraction of Creation and Real (de Miranda, 2008). Creal designates the capacity to envision, imagine or feel a creative and virtual cosmological source of the Real as a metaphysical "possibility of possibility" (Slife, 1994). The Creal is a simultaneously immanent and transcendent flow of ever-emerging potentiality which can be summarised in a simple modal formula: It is possible.

"There is a practical consciousness, an 'I can' that underlies and precedes the reflective self-consciousness of the 'I think', but the 'I can' is given and coeval with an 'it can'" (Sinclair, 2017, p. 191). As was understood by existentialist philosophers, chief among them Sartre and Heidegger, the universe is a possibilisation furnace. When one embodied living being says and feels, of a projected situation or idea for instance, that it's possible!, they are connecting with the modal creal spacetime. The embodied formula is-at least asymptotically—performative: it begins to produce something, it is the gateway to transform a virtuality into a reality, it possibilises, or crealectises, even if there is no deterministic 
link between the feeling or thought of possibility, and the actualisation or realisation of that impression (although a causal explanation can in some cases be given). The felt experience of possibility creates a bridge between, on the one hand, the apossible (from the alphaprivative prefix) or hypossible (from the Greek prefix hypo, meaning under or not yet), and on the other hand actualisation and realisation.

If we accept that the source of reality is driven by an infra-realist flux of infinite possibility, if the core of Being is the injunctive code "it's possible", then once embodied, this could be described as a cosmological dynamic of desire. Spinoza called this cosmic desire the conatus (Koistinen, 2014). The idea is also familiar in Daoism as the core of natural intelligence: "This desire is the source from which all things in the world arise and move toward fulfilment. [...] Desire, then, is what incites, animates, and furnishes the content of knowing" (Virág, 2017, p. 77). Our desire or lust for life can indeed feel cosmic or interstellar. We may tend to sexualise this feeling-but it is probable that sexuality is but a convincing ruse of evolution, in the sense that sexuality might have latched onto a prior available cosmic desire and by exaptation, part of this desiring energy was diverted to favour reproduction. Animals, insects and plants are likely to have a relationship to cosmic desire and possibility: the crealectic moment of our intelligence might respect them more than analytic or dialectic intelligences do.

The ultimate desire of crealectic embodiment could be said to be-following Lacan and Heidegger-without object (de Miranda, 2009). Crealectic consciousness would be attuned to the Creal and to pure desire which in the end would aim at itself rather than this or that. But, remembering the etymology of desire (longing for a lost star), I prefer to surmise with Plato and Plotinus that cosmic desire does have an aim that is logically induced by the multiplicity and infinite diversity of the Creal: pure unity, or "the One" (Wiitala, 2013, p. 649). We do not have the space here to enter in the details of the long philosophical relationship between the One and the Multiple, and how they might imply each other. Suffice it to say that if multiplicity and unity are the two logical sides of the same cosmological core, then the union with the One is that which all things desire, which is why Plato, Plotinus, and Aristotle called this prime mover the Good. An absolute unifying principle is the ultimate object of desire and the supreme Good from the perspective of the disparate. And from the perspective of unity, the ultimate Other is manifested by diversity and multiplicity: hence the primordial creative and psychological dialectics of "Dionysus" (attraction to multiplicity) and "Apollo" (attraction to unity), as explained in Nietzsche's Birth of Tragedy (Clewis, 2019, p. 223).

Influenced by Kant, the Romantic poet Wordsworth defined the play between "multitude" and "intense unity" as the essence of the "sublime" (Clewis, 2019, p.177). Crealectic intelligence transcends the borders of the actual and of the Real and therefore is related to the experience of sublimity. Artists have known or felt for long enough that "creativity as ultimate principle" (Whitehead, 1929, p. 31) is a relation with the intuitions of alterity and the sublime, "the incommensurability of reality to concept" (Lyotard, 1984, p. 79). Even for non-artistic practitioners, the experience of the sublime, for example in contemplating nature or in confronting a new culture, manifests itself as surreal or hyperreal awe, beyond the analytic routines: "Sublimity lifts the Absolute above every immediate existent and therefore brings about the liberation which, though abstract at first, is at least the foundation of the spirit" (Hegel, 1835, p. 362). 
Sublime feeling sensitizes us to an "outside and an inside" in thought, to a creative "hyper-dialectic" between imagination, reason, flesh, plurality and ambiguity (MerleauPonty, 1968, p. 94). A healthy human life and healthy thought needs to host regular moments of felt sublimity, as a necessary condition to reconnect with the possibility of regeneration or novelty. The intuition of creal sublimity becomes "the transport that leads all thought (critical thought included) to its limits" (Lyotard, 1994, x). This paradoxical capacity to pursue belief or knowledge about something we typically ignore, but feel or desire to be real, can be productive of new knowledge and new forms of dealing with existence: it suggests the effectual agency of what Einstein called "creative imagination" (Holton, 1978, p. 96).

The experience of awe, wonder, admiration or imaginative questioning, which Aristotle and Descartes considered to be the creative source of philosophy, are often seen as superfluous in sociotechnical protocols that are attached to an automated exhaustion or exploitation of the Real. Mundane practices of engineering or mathematical ordering tend to keep the imaginative or desiring subject out of their equations in order to achieve an operational description and management of a system or problem. The admirer, the contemplator, the observer, the practitioner, the interpreter, the dweller, the co-creator, are not accounting categories and can hardly be taken into account in predictive analytics. We can exemplify in many ways the horror that can be generated by hypertrophied forms of analytic intelligence: for instance, in the early 2000s, the French government introduced a computerized form of New Public Management into the organisation of their forests, via the Office National des Forêts. The results were negative: in 2019, a report from the Commission des Affaires Économiques of the French Parliament mentions a deep crisis in which no less than forty-eight forester employees committed suicide, out of a feeling of being deskilled, distrusted and treated like machines, while the diversity of the trees became endangered (Assemblée Nationale, 2019).

Such examples do not mean that computer intelligence will necessarily be the enemy of humanity, but that intelligent-systems designers need to carefully take into account the human need for a healthy cycle of analytic-dialectic-crealectic understanding. Human affairs can learn from creative philosophy and its practice of embodied knowledge (Foucault, 2005); and as the embodied reminiscence of the possibility of possibility, crealectics may also function as a politico-ethical global social contract (de Miranda, 2017). If we do not comprehend that the possibility of possibility should not be addressed only with computerised solutions, we might become indeed a self-domesticated robotic species (Arendt, 1958). In remaining open to the "creative generosity" of life (Canguilhem, 1991, p. 188), the democratisation of crealectic intelligence may allow for a new form of global consciousness. We cannot delegate crealectic thinking to a machine, since AI is devoid of the sense of desire, the sense of possibility and the sense of awe.

\section{Conclusion: From analytics to crealectics}

The "man-computer symbiosis" (Licklider, 1960) is not the ultimate horizon of humanity's destiny, but a sub-part of a higher form of interaction between humans and a ubiquitous process of desire, awe and possibilisation. We are not living in an artificial simulation in which the universe is merely reading its own program as it unfolds analytically, such as in 
the universal simulation hypothesis (Bostrom, 2003). Because of the feeling of desire in our bodies and the concept of possibility in our minds, which cannot be reduced to discrete bits of information, analytics is insufficient to understand our world and make the right decisions. The world can to a certain extent be divided into concrete analytic parts for the sake of manipulation and possession; it can partly be divided into dialectic tensions of agonistic unfolding to mediate power struggles, yet neither of these two forms of understanding exhaust the Real, because the Real as a mere set of things (res in Latin, and res extensa for Descartes) does not exhaust all there is.

Our existences are certainly embedded in mega-machinic sociotechnical digital systems, so complex that they might even suggest a "technological sublime" (Jameson, 1984, p. 79): systems of hyper-surveillance and control under the guise of dreamlike divertissement, education and emotional relationships via handheld devices, all the mysterious aspects of everyday life are now touched by AI. Human nature can be at least partly defined as "anthrobotic", a combination of flesh and protocols, but we are not merely one polarity of a machine-human dialectic, because we remain — for the time being-emotionally, intuitively and intellectually touched by creative sublimity. Philosophy is not only about a form of logic but also about "a form of life" (Wittgenstein, 1958, p. 11). On top of analytical or dialectical transactions, the crealectical subject is a thinker who cares to take holistic decisions towards a philosophically healthier way of life.

\section{References}

Alexander of Aphrodisias (c.200 CE /1991). On Aristotle's prior analytics (J. Barnes, Trans.). London: Duckworth.

Arendt, H. (1958). The human condition. Chicago: University of Chicago Press.

Arnauld, A., \& Nicole, P. (1996). Logic or the art of thinking. (J.V. Buroker, Trans.). Cambridge: Cambridge University Press.

Assemblée Nationale Française (2019). Compte-rendu 28 [Account of debate 28], Commission des Affaires Économiques, 11 Décembre 2019.

Bergson, H. (1922). Creative evolution (A. Mitchell, Trans.). London: MacMillan.

Berthoz, A. (2012). Simplexity: Simplifying principles for a complex world. New Haven: Yale University Press.

Bloch, E. (1983). The dialectical method (J. Lamb, Trans.). Man and World, 16(4), 281-313.

Bostrom, N. (2003). Are we living in a computer simulation? Philosophical Quarterly, 53(211), 243-55.

Canguilhem, G. (1991). The normal and the pathological (C. R. Fawcett, Trans.). New York: Zone Books.

Chandler, D., \& Munday, R. (2016). Dictionary of social media. (3rd ed.). Oxford: Oxford University Press.

Chomsky, N. (1968). Language and mind. New York: Harcourt Brace Jovanovich.

Clewis, R. R. (2019). The sublime reader. London: Bloomsbury.

Craig, R. P. (1984). Developing a philosophy of reading: Piaget and Chomsky. Reading Horizons, $25(1), 38-42$.

Deleuze, G., \& Guattari, F. (1994). What is philosophy? (H. Tomlinson \& G. Burchell, Trans.). New York: Columbia University Press.

De Miranda, L. (2008). Paridaiza. Paris: Plon. 
De Miranda, L. (2009). Peut-on jouir du capitalisme? Lacan avec Heidegger et Marx [Can we enjoy capitalism? Lacan with Heidegger and Marx]. Paris: Max Milo.

De Miranda, L., Ramamoorthy R., \& Rovatsos, M. (2016). We, anthrobot: Learning from human forms of interaction and esprit de corps to develop more diverse social robotics. In What Social Robots Can and Should do (pp. 48-56). Amsterdam: IOS Press.

De Miranda (2017). On the concept of Creal: The politico-ethical horizon of a creative absolute. In The Dark Precursor: Deleuze and Artistic Research (pp. 510-16). Louvain: Leuven University Press.

De Miranda, L. (2019). Being and neonness. Cambridge, MIT Press.

De Miranda, L. (2020). Ensemblance: The transnational genealogy of esprit de corps. Edinburgh: Edinburgh University Press.

Elbow, P. (1993). The uses of binary thinking. Journal of Advanced Composition 13(1), 51-78.

Foucault (2005). The hermeneutics of the subject. (G. Burchell, Trans.). New York: Palgrave Macmillan.

Geraci, R. M. (2008). Apocalyptic AI: Religion and the promise of artificial intelligence. Journal of the American Academy of Religion, 76(1), 138-66.

Hegel, G.W.F (1806/1984). Letter to Friedrich Niethammer, 13 October 1806. In C. Butler \& C. Seiler (Trans.), The Letters. Bloomington: Indiana University Press.

Hegel, G.W.F. (1835/1975). Aesthetics: Lectures on fine art (Vol 1, p. 362). (T.M. Knox, Trans.). Oxford: Oxford University Press.

Hegel, G.W.F. (1817/1991). The encyclopaedia logic (T.F. Geraets, W.A. Suchting \& H.S. Harris, Trans.). Indianapolis: Hackett.

Holton, G. (1978). The scientific imagination: Case studies. Cambridge: Cambridge University Press.

Jameson, F. (1984) Postmodernism, or the cultural logic of late capitalism. New Left Review 1(146), $76-80$.

Jousse, M. (2016). In search of coherence (E. Sienaert, Trans.). Eugene: Pickwick Publications.

Kaan, E. (1999). Syntax and semantics? Trends in Cognitive Sciences, 3 (9), 322.

Koistinen, O. (2014). Desire and good in Spinoza. In M.J. Kisner \& A. Joupa (Eds.), Essays on Spinoza's Ethical Theory. Oxford: Oxford University Press.

Laplace, P. S. (1814/1902). A philosophical essay on probabilities. (F.W. Truscott \& F. L. Emory, Trans.). New York: Wiley and Sons.

Licklider (1960). Man-computer symbiosis. IRE Transactions on Human Factors in Electronics, HFE$1(1), 4-11$.

Lyotard, J.-F. (1984). The Postmodern Condition: A Report on Knowledge (G. Bennington \& B. Massumi, Trans.). Minneapolis: University of Minnesota Press.

Lyotard, J.-F. (1994). Lessons on the Analytic of the Sublime (E. Rottenberg, Trans.). Stanford: Stanford University Press.

McMahon, D. M. (2013). Divine fury: A history of genius. New York: Basic Books.

Menabrea, L. F. (1961). Sketch of the analytical engine invented by Charles Babbage. In P. Morrison \& E. Morrison (Eds.), Charles Babbage and his calculating engines; selected writings by Charles Babbage and others (pp. 225-297). New York: Dover.

Merleau-Ponty, M. (1968). The visible and the invisible. (A. Lingis, Trans.). Evanston: Northwestern University Press.

Murphy, N., \& Stoeger, W. R. (2007). Evolution and emergence: Systems, organisms, persons. Oxford: Oxford University Press.

Piaget, J. (1952). The origins of intelligence in children. New York: W. W. Norton.

Quine, W. V., \& Ullian, J. S. (1978). The web of belief. New York: McGraw-Hill Education.

Russell, S. J. (2019). Human compatible: Artificial intelligence and the problem of control. New York: Viking. 
Ryle, G. (2009). The Concept of Mind. London and New York: Routledge.

Searle, J. (1980). Minds, brains and programs. Behavioral and Brain Sciences, 3(3), 417-457.

Searle, J. (2010). Why dualism (and materialism) fail to account for consciousness. In R.E. Lee (Ed.), Questioning nineteenth century assumptions about knowledge. New York: Suny Press.

Sinclair, M. (2017). The actual and the possible: Modality and metaphysics in modern philosophy. Oxford: Oxford University Press.

Slife, B. D. (1994). The possibility of possibility. Journal of Theoretical and Philosophical Psychology, 14 (1), 96-101.

Thompson, H. E. (1997). The fallacy of misplaced concreteness: Its importance for critical and creative inquiry. Interchange, $28(2 \& 3)$, pp. 219-30.

Turing, A. M. (1950). Computing machinery and intelligence. Mind, 59, 433-460.

Virág, C. (2017). The Emotions in Early Chinese Philosophy. Oxford: Oxford University Press.

Whitehead, A.N. (1926). Science and the modern world. Cambridge, Cambridge University Press.

Whitehead, A. N. (1929). Process and reality. New York: MacMillan.

Wiitala, M. O. (2013). Desire and the Good in Plotinus. British Journal for the History of Philosophy, 21(4), 649-666.

Wittgenstein, L. (1958). Philosophical investigations (G.E.M. Anscombe, Trans.). Oxford: Blackwell.

Örebro University

Fakultetsgatan 1

70281 Örebro

Sweden

Email: luis.de-miranda@oru.se 